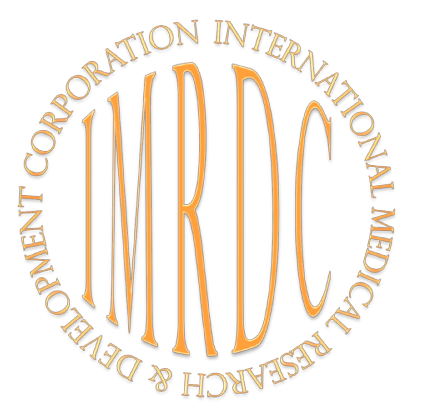

\title{
The Assessment of Oxidative Stress Intensity in Adolescents with Obesity by the Integral Index
}

\author{
Marina A. Darenskaya, $\mathrm{PhD}, \mathrm{ScD}^{1}$; Oksana A. Gavrilova ${ }^{1}$; Lyubov V. Rychkova, $\mathrm{PhD}, \mathrm{ScD}^{1}$; \\ Olga V. Kravtsova, $\mathrm{PhD}^{1}$; Lyudmila A. Grebenkina, $\mathrm{PhD}, \mathrm{ScD}^{1}$; Elena V. Osipova, $\mathrm{PhD}, \mathrm{ScD}^{1,2}$; \\ Sergey I. Kolesnikov, Academician of the RAS ${ }^{1,3}$; Lyubov I. Kolesnikova, Academician of the RAS ${ }^{1}$

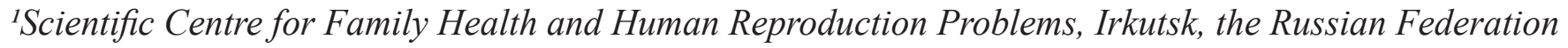 \\ ${ }^{2}$ Irkutsk State University, Irkutsk, the Russian Federation \\ ${ }^{3}$ M.V. Lomonosov Moscow State University, Moscow, the Russian Federation
}

\begin{abstract}
The aim of this research was to assess lipid peroxidation (LPO) and antioxidative defense (AOD) changes in adolescent boys with obesity using the integral index.

Materials and Methods: We examined 19 adolescent boys with obesity of the first degree (the study group). The control group included 23 healthy adolescent boys. The study included the collection of anamnestic data, physical examination, and anthropometric data analysis (body weight (BW), height, waist circumference (WC), hip circumference (HC), and body mass index (BMI)). Laboratory analysis included an assessment of the blood levels of total cholesterol, triglycerides, HDL, LDL, and glucose, as well as the intensity of LPO and AOD in blood plasma and primary and secondary products of LPO. To measure the intensity of OS, the oxidative stress index (OSi) was calculated (the ratio of the LPO-AOD system indicators in the study group to average indicators in the control group).

Results: We found a statistically significant increase in BW, BMI, SDS BMI, WC, and HC in the study group compared to the control group. The obese patients had higher values of blood glucose, total cholesterol, triglycerides and LDL compared to the control group. In the study group, we found a significant decrease in the concentration of diene conjugates and an increase in the level of ketodienes and conjugated trienes. The values of $\alpha$-tocopherol and retinol, and SOD activity were significantly decreased in the study group compared to the control group. There were no statistically significant changes in total antioxidant activity and glutathione status components. According to the data received, the OSi level in the group of obese patients increased approximately 7 times, which confirms the results on the development of antioxidant insufficiency in this pathology.(International Journal of Biomedicine. 2018;8(1):37-41.)
\end{abstract}

Key Words: lipid peroxidation $\bullet$ antioxidative defense $\bullet$ oxidative stress index $\bullet$ adolescent boys $\bullet$ obesity

\section{Abbreviations}

AOD, antioxidative defense; BMI, body mass index; BW, body weight; CDs, conjugated dienes; GSH, reduced glutathione; GSSG, oxidized glutathione; HC, hip circumference; HDL, high-density lipoprotein; KD-CT, ketodienes and conjugated trienes; LDL, low-density lipoprotein; LPO, lipid peroxidation; OS, oxidative stress; SDS BMI, the standard deviation score of BMI; SOD, superoxide dismutase; TAA, total antioxidant activity; TBARs, thiobarbituric acid reactants; WC, waist circumference.

\section{Introduction}

Childhood obesity is a serious medical condition that affects children and adolescents. In the developed countries, $25 \%$ of adolescents have excessive body weight and $15 \%$ have obesity. ${ }^{(1-4)}$ The incidence of obesity is $6.8 \%$ in boys
5 to 17 years old and $5.3 \%$ in girls. ${ }^{(5)}$ Childhood obesity usually progresses and often leads to health problems in adulthood: hypertension, metabolic syndrome, diabetes, and cardiovascular and fatty liver diseases.

WHO experts connect the prevalence of obesity in childhood with economic and social changes of life in a 
modern society, unhealthy diets, and low physical activity. ${ }^{(6,7)}$ The study of molecular mechanisms of obesity formation in adolescence is very important. ${ }^{(8-10)}$ One of the pathogenetic mechanisms of obesity development is OS activation and a decrease in AOD activity. ${ }^{(11-15)}$ Endogenous aldehydes generated during OS can act as mediators of damage, which precedes the emergence of metabolic shifts. ${ }^{(14)}$

The aim of this research was to assess LPO and AOD changes in adolescent boys with obesity using the integral index.

\section{Materials and Methods}

We examined 19 adolescent boys (mean age of $4.41 \pm 0.45$ years) with obesity of the first degree (the study group) according to the WHO classification. ${ }^{(16)}$ The control group included 23 healthy boys (mean age of $15.12 \pm 0,32$ years). The study included the collection of anamnestic data, physical examination, and anthropometric data analysis (BW, height, WC, HC, and BMI). BMI was calculated using Quetelet's formula:

$\mathrm{BMI}=$ body weight $(\mathrm{kg}) /$ height $(\mathrm{cm})^{2}$

Laboratory analysis included an assessment of the blood levels of total cholesterol, triglycerides, HDL, LDL, and glucose. The quality, quantity and regularity of food intake were evaluated. Hereditary anamnesis included the presence of relatives with type 2 diabetes, obesity, ischemic heart disease, and hypertension. All patients did not take vitamins during the blood sampling period.

Blood was taken from the ulnar vein in accordance with the existing requirements in the morning after an overnight fast. Blood samples were centrifuged for $5 \mathrm{~min}$ at $1.500 \mathrm{~g}$ at $4{ }^{\circ} \mathrm{C}$; erythrocytes were rinsed three times with $0.9 \%$ $\mathrm{NaCI}$. Aliquots of the separated EDTA plasma and washed erythrocytes were used immediately or kept frozen at $-40^{\circ} \mathrm{C}$ (not longer than one month).

We estimated the intensity of LPO and AOD in blood plasma (TAA, SOD, GSH, GSSG, $\alpha$-tocoferol, retinol) and primary and secondary products of LPO (CDs, ketodienes, KD-CT and TBARs). The concentrations of CDs and KD-CT were evaluated at $232 \mathrm{~nm}$ in plasma heptane extracts. ${ }^{(17)}$ The coefficient of molar absorption $(\mathrm{K}=2.2 \cdot 105 \mathrm{M}-1 \mathrm{C}-1)$ for conversion of absorption units to $\mu \mathrm{mol} / \mathrm{L}$ was used. TBARs levels were detected by fluorometry ${ }^{(18)}$ and estimated in $\mu \mathrm{mol} / \mathrm{L}$.

Plasma levels of GSH, GSSG, $\alpha$-tocopherol and retinol, as well as SOD activity in hemolysate were detected by fluorometry.(19-21) Plasma TAA levels were detected photometrically. ${ }^{(22)}$ The measurements were conducted by a spectrophotometer consisting of two blocks: a UV-1650PC spectrophotometer and an RF-1501 spectrofluorimeter. To measure the intensity of OS, the oxidative stress index (OSi) was calculated (the ratio of the LPO-AOD system indicators in the study group to average indicators in the control group)..$^{(23)}$

The study was conducted in accordance with ethical principles of the WMA Declaration of Helsinki (1964, ed. 2000) and approved by the Ethics Committee of Scientific Centre for Family Health and Human Reproduction Problems. Written informed consent was obtained from all participants.
Statistical analysis was performed using the statistical software «Statistica». (v6.1, StatSoft, USA). The mean (M) and standard deviation (SD) were calculated. For data with normal distribution, inter-group comparisons were performed using Student's t-test. Differences of continuous variables departing from the normal distribution, even after transformation, were tested by the Mann-Whitney $U$-test. A probability value of $\mathrm{P}<0.05$ was considered statistically significant.

\section{Results and Discussion}

We found a statistically significant increase in BW (1.48 times, $\mathrm{P}<0.001)$, BMI (1.5 times, $\mathrm{P}<0.0001$, SDS BMI (12.43 times, $\mathrm{P}<0.0001)$, WC ( 1.35 times, $\mathrm{P}<0.0001$, and $\mathrm{HC}(1.21$ times, $\mathrm{P}<0.0001)$ in the study group compared to the control group. In obese patients, we found an increase of 1.4 times in glucose level $(\mathrm{P}=0.028)$, which can be explained by impaired glucose tolerance. ${ }^{(24)}$ The obese patients had higher values of total cholesterol, triglycerides and LDL compared to the control group (Table 1). According to a number of authors, changes in the blood lipids in children with obesity depend on the severity of the disease. ${ }^{(25)}$

Table 1.

Clinical characteristics and biochemical parameters in adolescents of the study and control groups

\begin{tabular}{|l|c|c|}
\hline \multicolumn{1}{|c|}{ Variable } & Control group & Study group \\
\hline Age, years & $15.69 \pm 1.49$ & $14.58 \pm 1.98$ \\
\hline Weight, kg & $64.83 \pm 9.17$ & $95.82 \pm 15.06^{*}$ \\
\hline Height, cm & $174.20 \pm 9.17$ & $173.40 \pm 8.93$ \\
\hline BMI & $21.25 \pm 1.01$ & $31.79 \pm 3.61^{*}$ \\
\hline SDS BMI & $0.23 \pm 0.30$ & $2.86 \pm 0.51^{*}$ \\
\hline WC, cm & $73.20 \pm 4.53$ & $99.10 \pm 8.49^{*}$ \\
\hline HC, cm & $88.00 \pm 4.00$ & $106.2 \pm 6.65^{*}$ \\
\hline Total cholesterol, $\mu \mathrm{mol} / \mathrm{L}$ & $3.43 \pm 0.44$ & $4.83 \pm 0.64^{*}$ \\
\hline Triglycerides, $\mu \mathrm{mol} / \mathrm{L}$ & $0.43 \pm 0.16$ & $1.63 \pm 0.52^{*}$ \\
\hline HDL, $\mu \mathrm{mol} / \mathrm{L}$ & $1.10 \pm 0.24$ & $1.18 \pm 0.38$ \\
\hline LDL, $\mu \mathrm{mol} / \mathrm{L}$ & $2.75 \pm 0.39$ & $2.83 \pm 1.06^{*}$ \\
\hline Glucose, $\mu \mathrm{mol} / \mathrm{L}$ & $4.02 \pm 1.66$ & $5.64 \pm 1.29^{*}$ \\
\hline
\end{tabular}

* $-P<0.05$ vs. the control group

In the study group, we found a significant decrease in the concentration of diene conjugates (primary products of LPO) and an increase in the level of ketodienes and conjugated trienes (secondary products of LPO) on the background of the absence of statistically significant changes in the content of TBA-active products (Table 2). The obtained results partly agree with multiple research data showing that obesity stimulates the processes of free radical oxidation, and the resulting OS acts as one of the pathogenetic mechanisms of obesity. Over-expression of OS damages cellular structures together with under-production of anti-oxidant mechanisms, 
leading to the development of obesity-related complications. (26) It was found that the increased content of ketodienes and conjugated trienes might provoke a multifaceted deleterious effect on biopolymers and cellular structures. In obesity, increased OS in plasma is due to increased ROS production from accumulated fat Shigetada Furukawa and colleagues suggested that obesity per se may induce systemic OS stress and that increased OS in accumulated fat is, at least in part, the underlying cause of dysregulation of adipocytokines and development of metabolic syndrome. ${ }^{(11)}$ OS plays a crucial role in disorders related to obesity, such as dyslipidemia. ${ }^{(26)}$ In addition to a pro-inflammatory process, ROS can also directly damage lipids, proteins or DNA and modulate intracellular signalling pathways, such as mitogen activated protein kinases and redox sensitive transcription factors, causing changes in protein/lipid expression and, therefore, irreversible oxidative damage. ${ }^{(27)}$ Due to ROS-mediated changes in lipid expression, further oxidation-derived products, including oxidative LDL (Ox-LDL), can play a further critical role in CVD. Additionally, Ox-LDL alters the production of adipokines which can lead to further OS. ${ }^{(26,28)}$ Increased Ox-LDL in obese patients with dyslipidemia may be due to loss of antioxidant capacity caused by low serum activity of the antioxidant enzyme (SOD). ${ }^{(29)}$

\section{Table 2.}

Indicators of LPO and AOD in blood plasma

\begin{tabular}{|l|c|c|}
\hline \multicolumn{1}{|c|}{ Variable } & Control group & Study group \\
\hline CDs, $\mu \mathrm{mol} / \mathrm{L}$ & $2.32 \pm 0.74$ & $1.67 \pm 0.71^{*}$ \\
\hline KD-CT, units & $0.26 \pm 0.12$ & $0.43 \pm 0.26^{*}$ \\
\hline TBA-active products, $\mu \mathrm{mol} / \mathrm{L}$ & $0.86 \pm 0.45$ & $0.97 \pm 0.48$ \\
\hline TAA, units & $15.73 \pm 3.52$ & $15.39 \pm 4.43$ \\
\hline$\alpha$-tocopherol, $\mu \mathrm{mol} / \mathrm{L}$ & $8.15 \pm 2.8$ & $5.75 \pm 3.38^{*}$ \\
\hline retinol, $\mu \mathrm{mol} / \mathrm{L}$ & $0.68 \pm 0.21$ & $0.45 \pm 0.24^{*}$ \\
\hline SOD activity, units & $1.69 \pm 0.1$ & $1.42 \pm 0.29^{*}$ \\
\hline GSH, mmol/L & $2.29 \pm 0.22$ & $2.12 \pm 0.45$ \\
\hline GSSG, mmol/L & $1.94 \pm 0.22$ & $1.89 \pm 0.47$ \\
\hline
\end{tabular}

* $-P<0.05$ vs. the control group

The AOD system involving special antioxidant enzymes (SOD, catalase, enzymes of the glutathione redox system, water- and fat-soluble vitamins) plays an important role in protecting the body from oxidative damage. ${ }^{(26,30)}$ Dysfunction of the AOD system is characterized by the development of the LPO syndrome and can lead to a number of negative consequences for the cell, such as membrane damage, inactivation or transformation of enzymes, suppression of cell division, and accumulation of inert polymers. ${ }^{(11,26)} \mathrm{We}$ found a decrease in the values of $\alpha$-tocopherol ( 1.42 times, $\mathrm{P}=0.0158$ ) and retinol (1.51 times, $\mathrm{P}=0.0025)$, and SOD activity (1.19 times, $\mathrm{P}=0.0001$ ) in the study group compared to the control group (Table 2). There were no statistically significant changes in TAA and glutathione status components.
It has been established that even a slight decrease in SOD activity is an important signal of a metabolic shift towards the prevalence of prooxidant processes. $\alpha$-tocopherol and retinol are the strongest bioantioxidants and the necessary nutritive factors. ${ }^{(30)}$ Moreover, $\alpha$-tocopherol shows membraneprotective and antimutagenic activity and is the most important regulator of oxidative homeostasis of cells. The in vitro and in vivo evidence of the function of vitamin $\mathrm{E}$ as a peroxyl radicalscavenging antioxidant and inhibitor of lipid peroxidation is presented in study by E.Niki. ${ }^{(31)}$ According to many studies, vitamin A in large doses increased the antioxygenic potential of the tissues, and it was suggested that retinol also might be considered as a potential antioxidant similar to tocopherol. ${ }^{(32-34)}$

It seems optimal to use OSi because multidirectional changes occur in the LPO-AOD system with the development of various pathological conditions. For that purpose, the formula for OSi calculation was developed in our previous study ${ }^{(23)}$ :

$\mathrm{OSi}=\left(\mathrm{CDs}_{\mathrm{i}} / \mathrm{CDs}_{\mathrm{n}}\right) \times\left(\mathrm{KD}-\mathrm{CT}_{\mathrm{i}} / \mathrm{KD}-\mathrm{CT}_{\mathrm{n}}\right) \times(\mathrm{TBA}$-active products $_{\mathrm{i}} / \mathrm{TBA}$-active-products $\left.\mathrm{n}\right) /\left(\mathrm{SOD}_{\mathrm{i}} / \mathrm{SOD}_{\mathrm{n}}\right) \times\left(\mathrm{GSH}_{\mathrm{i}} /\right.$ $\left.\mathrm{GSH}_{\mathrm{n}}\right) \times(\alpha$-tocopherol $/ \boldsymbol{\alpha}$-tocopherol $) \times\left(\right.$ retinol $_{\mathrm{i}} /$ retinol $\left._{\mathrm{n}}\right)$,

where $\mathrm{i}$ - the indicators levels in obese patients, $\mathrm{n}$ - the indicators levels in the control group.

OSi $>1$ shows the presence of OS. This formula takes into account not only the accumulation of LPO products at various stages, but also the activity of various parts of the AOD system. According to the data received, the OSi level in the group of obese patients increased approximately 7 times, which confirms the results on the development of antioxidant insufficiency in this pathology (Fig.1).

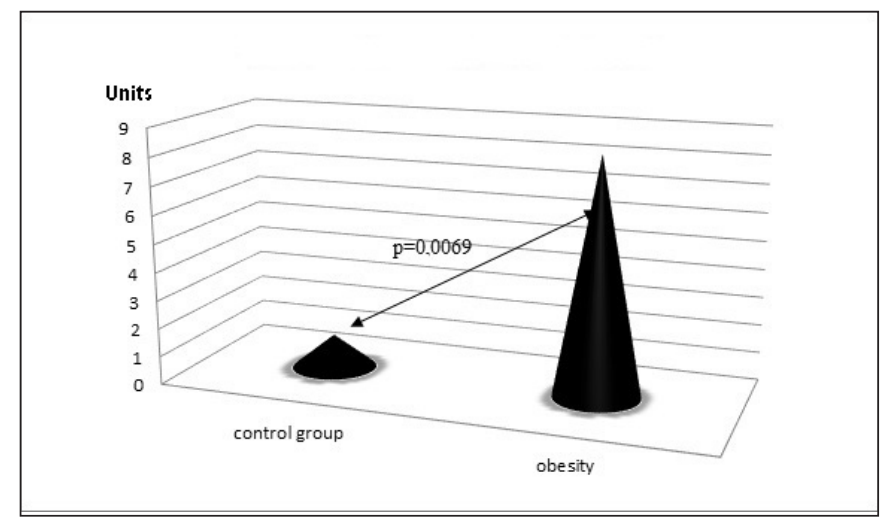

Fig.1. Oxidative stress index (OSi)

\section{Conclusion}

Thus, our study showed certain features of the changes in the LPO-AOD system in adolescent boys with obesity: a decrease in levels of primary LPO products and an increase in the level of secondary LPO products on the background of reducing the fat-soluble vitamins and SOD activity. The use of OSi confirmed the presence of antioxidant deficiency in adolescents with obesity. 


\section{Competing interests} interests.

The authors declare that they have no competing

\section{References}

1. Tutelyan VA, Baturin AK, Kon IYa, Martinchik AN, Uglitskikh AK, Korosteleva MM, et al. [Prevalence of overweight and obesity in child population of Russia: multicenter study]. Journal "Pediatria" named after G.N. Speransky. 2014;93(5):28-31. [Article in Russian].

2. Pollack HA. The Problem of Obesity. J Health Polit Policy law. 2016;41(3):451-2. doi: 10.1215/03616878-3523996

3. Kirk S, Armstrong S, King E, Trapp C, Grow M, Tucker J et al. Establishment of the Pediatric Obesity Weight Evaluation Registry: A National Research Collaborative for Identifying the Optimal Assessment and Treatment of Pediatric Obesity. Child Obes. 2017;13(1):9-17. doi: 10.1089/chi.2016.0060.

4. Zhang Y, Wang S. Differences in development and the prevalence of obesity among children and adolescents in different socioeconomic status districts in Shandong, China. Ann Hum Biol. 2012;39(4):290-6. doi: 10.3109/03014460.2012.690888

5. Soboleva NP, Rudnev SG, Nikolayev DV, Eryukova TA, Kolesnikov VA, Melnitchenko OA, et al. [The bio-impedance screening of population in health centers: prevalence of surplus body mass and obesity]. Medical Journal of the Russian Federation. 2014;4:4-13. [Article in Russian].

6. Wimalawansa SJ. Controlling obesity and its complications by elimination of causes and adopting healthy habits. Advances in Medical Sciences. 2014;3(1):1-15.

7. Camacho S, Ruppel A. Is the calorie concept a real solution to the obesity epidemic? Global Health Action. 2017;10(1):1289650. doi: 10.1080/16549716.2017.1289650.

8. Guénard F, Houde A, Bouchard L, Tchernof A, Deshaies Y, Biron S et al. Association of LIPA gene polymorphisms with obesity-related metabolic complications among severely obese patients. Obesity (Silver Spring). 2012 Oct;20(10):207582. doi: 10.1038/oby.2012.52.

9. Kolosov JuA, Kolesnikov SI, Anishhenko AP, Burdyukova EV, Gurevich KG. [Overweight and obesity in children, adolescents and adults: causes of development and risk factors]. Pathogenesis. 2016;14(4):9-14. [Article in Russian]. 10. Bost KK, Teran-Garcia M, Donovan SM, Fiese BH, STRONG Kids Team. Child body mass index, genotype and parenting in the prediction of restrictive feeding. Pediatric Obesity. 2017 Apr 21. doi: 10.1111/ijpo.12219. [Epub ahead of print]

11. Furukawa S, Fujita T, Shimabukuro M. Iwaki M., Yamada Y, Nakajima Y et al. Increased oxidative stress in obesity and its impact on metabolic syndrome. J Clin Invest. 2017;114(12):1752-61.

12. Kuleshova K, Davydov VV. Some peculiarities in the manifestation of oxidative stress and current status of antioxidant system in adolescents of different age groups with obesity, complicated by insulin resistance and without it. Biomeditsinskaya Khimiya. 2014;60(2):264-274. [Article

*Corresponding author: Marina A. Darenskaya, PhD, ScD. Scientific Centre for Family Health and Human Reproduction Problems, Irkutsk, the Russian Federation.E-mail: marina darenskaya@inbox.ru in Russian].

13. Kolesnikova LI, Dolgikh VV, Polyakov VM, Rychkova LV. Problems of psychosomatic pathology of childhood age. Novosibirsk; 2005. [In Russian].

14. Darenskaya MA, Rychkova LV, Kolesnikov SI, Gavrilova OA, Kravtsova OV, Grebenkina LA, Kolesnikova LI Oxidative stress parameters in adolescent boys with exogenousconstitutional obesity. Free Radical Biology \& Medicine. 2017;112:129-130.

15. Kolesnikova LI, Dolgikh VV, Prokhorova ZV, Grebenkina LA, Vlasov BY, Ilyin VP. [Peculiarities of the state of the system of lipid peroxidation of antioxidant protection and exchange of calcium in children of adolescent age in essential arterial hypertension]. Journal "Pediatria" named after G.N. Speransky. 2010;83(3):10-14. [Article in Russian].

16. WHO. BMI-for-age (5-19 years) Available from: http:// www.who.int/growthref/who2007_bmi_for_age/en/

17. Volchegorskij IA, Nalimov A $\bar{G}$, Jarovinskij BG. [Comparison of different approaches to the determination of lipid peroxidation products in heptane-isopropanol extracts of blood]. Voprosi Med Khimii. 1989;35(1):127-131. [Article in Russian].

18. Gavrilov VB, Gavrilova AR, Mazhulin LM. [Analysis of methods for determining products of peroxide oxidation of lipids in blood serum according to the test with thiobarbituric acid]. Voprosi Med Khimii. 1987;1:118-122. [Article in Russian].

19. Hisin PJ, Hilf R. A fluorometric method for determination of oxidized and reduced glutathione in tissues. Anal Biochem. 1976;74:214-26.

20. Misra HP, Fridovich I. The role of superoxide anion in the autoxidation of epinephrine and a simple assay for superoxide dismutase. J Biol Chem. 1972;247(10):3170-5.

21. Cherniauskene RCh, Varshkiavichene ZZ, Gribauskas PS. [Simultaneous fluorometric determination of the concentrations of vitamins E and A in blood serum]. Lab Delo. 1984;(6):362-65. [Article in Russian].

22. Klebanov GI, Babenkova IV, Teselkin IuO, Komarov OS, Vladimirov IuA. [Evaluation of the antioxidative activity of blood plasma using yolk lipoproteins]. Lab Delo. 1988;(5):5962. [Article in Russian].

23. Kolesnikova LI, Semyonova NV, Grebenkina LA, Darenskaya MA, Suturina LV, Gnusina S. Integral indicator of oxidative stress in human blood. Bull Exp Biol Med. 2014;157(6):715-7. doi: 10.1007/s10517-014-2649-z.

24. Zagoruiko MV, Bardymova TP, Rychkova LV. [Obesity in children and adolescents]. Siberian Medical Journal (Irkutsk). 2010;97(6):16-19.[Article in Russian].

25. Fucho R, Casals N, Serra D, Herrero L. Ceramides and mitochondrial fatty acid oxidation in obesity. FASEB J. 2017;31(4):1263-72. doi: 10.1096/fj.201601156R.

26. Marseglia L, Manti S, D'Angelo G, Nicotera A, Parisi E, Di Rosa $G$ et al. Oxidative stress in obesity: a critical component in human diseases. Int J Mol Sci. 2014;16(1):378400. doi:10.3390/ijms 16010378

27. Ceriello A, Taboga C, Tonutti L, Quagliaro L, Piconi L, Bais B, Da Ros R, Motz E. Evidence for an independent and cumulative effect of postprandial hypertriglyceridemia and hyperglycemia on endothelial dysfunction and oxidative stress generation: effects of short- and long-term simvastatin treatment. Circulation. 2002;106(10):1211-8.

28. Parthasarathy S, Raghavamenon A, Garelnabi MO, Santanam N. Oxidized low-density lipoprotein.Methods Mol 
Biol. 2010;610:403-17. doi: 10.1007/978-1-60327-029-8 24. 29. Wang B, Trayhurn P. Acute and prolonged effects of TNFalpha on the expression and secretion of inflammation-related adipokines by human adipocytes differentiated in culture. Pflugers Arch. 2006;452(4):418-27.

30. Kolesnikova LI, Darenskaja MA, Grebenkina LA, Osipova EV, Dolgikh MI, Natyaganova LV. [ The state of the antioxidant status of children of different ages]. Vopr Pitan. 2013;82(4):27-33. [Article in Russian].

31. Niki E. Role of vitamin $E$ as a lipid-soluble peroxyl radical scavenger: in vitro and in vivo evidence. Free Radical Biology and Medicine. 2014;66:3-12.

32. Kartha VN, Krishnamurthy S.Antioxidant function of vitamin A.Int J Vitam Nutr Res. 1977;47(4):394-401.

33. Kodentsova VM, Vrzhesinskaia OA, Mazo VK. [Vitamins and oxidative stress]. Vopr Pitan 2013;82(3):11-8. [Article in Russian].

34. Dao DQ, Ngo TC, Thong NM, Nam PC. Is Vitamin A an Antioxidant or a Pro-oxidant? J Phys Chem B. 2017;121(40):93489357. doi: 10.1021/acs.jpcb.7b07065. 